Revistade
Economild
Contemporâned

\title{
PROMESSAS DE UM LIBERALISMO TARDIO: UMA ANÁLISE DAS POLÍTICAS ECONÔMICAS DO GOVERNO MACRI (2015-2019)
}

\author{
Alexandre Jeronimo de Freitas ${ }^{a}$ \\ Javier Walter Ghibaudi ${ }^{b}$ \\ Eduardo Alberto Crespo ${ }^{c}$ \\ aProfessor Associado da Universidade Federal Rural do Rio de Janeiro (UFRRJ). Seropédica, RJ, Brasil. \\ ORCID: https://orcid.org/0000-0003-3397-5210. \\ bProfessor Adjunto da Universidade Federal Fluminense (UFF). Niterói, RJ, Brasil. \\ ORCID: https://orcid.org/0000-0003-3559-7022.

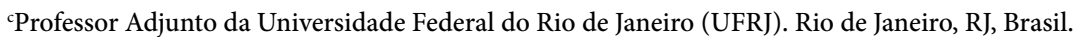 \\ ORCID: https://orcid.org/0000-0003-1638-5390. \\ Recebido em 16 dezembro 2019 \\ Aceito em 06 abril 2021 \\ RESUMO: Após 12 anos de governos kirchneristas, uma coalização política liberal- \\ conservadora consegue ganhar o poder na Argentina em 2015. Prometendo um retorno \\ ao mundo com abertura comercial e liberalização econômica, o governo de Mauricio \\ Macri chegou a seu último ano em uma grave crise econômica. O objetivo deste artigo \\ é analisar de que forma as reformas econômicas promovidas pelo governo deterioraram \\ significativamente as perspectivas futuras para economia argentina.
}

PALAVRAS-CHAVE: economia argentina; governo Macri; endividamento externo.

CLASSIFICAÇÃO JEL: E10; E63; F10.

Correspondência para: Alexandre Jeronimo de Freitas

Contato: alexandrefreitas76@ufrrj.br 


\title{
PROMISES OF A LATE LIBERALISM: AN ANALYSIS OF THE MACRI GOVERNMENT'S ECONOMIC POLICIES (2015-2019)
}

\begin{abstract}
After 12 years of Kirchner's governments, a liberal-conservative political coalition manages to gain power in 2015 in Argentina. Promising a return to the world trough commercial openness and economic liberalization, President Macri's government reached its last year in serious economic crisis. This article aims to analyze how the economic reforms promoted by the government seriously aggravated the future perspectives of Argentinean economy.
\end{abstract}

KEYWORDS: Argentine economy; Macri’s government; external indebtedness. 


\section{INTRODUÇÃO'}

Em 2019, a Argentina passou por novas eleições presidenciais. A coalização política que governou o país desde meados de 2015, Cambiemos, buscou a reeleição, porém, país passava por uma situação de grave crise econômica.

Tratava-se do primeiro governo com um programa explícito de mudanças conservadoras e liberais que tinha chegado ao poder pelo voto popular (VOMMARO, 2019). Suas próprias lideranças usaram como trunfo seu pertencimento aos setores mais tradicionais das elites e seu histórico projeto de abertura comercial e financeira, além da regulação dos mercados em favor das orientações dos agentes privados.

Desta forma, triunfava democraticamente o campo conservador que, pelo menos desde o fim da Segunda Guerra Mundial, se opôs aos projetos de industrialização e redistribuição da renda que mobilizaram a classe trabalhadora e amplos setores meios. Trata-se de um conflito que o debate argentino tem denominado como “empate hegemônico" pela indefinição permanente entre projetos políticos antagônicos (PORTANTIERO, 2019; O’DONNELL, 1977).

Se o projeto liberal-conservador foi tentado em diversos períodos, o processo ocorreu, na maioria dos casos, em períodos antidemocráticos, notadamente o período da última ditadura (1976-1983), mas também através de políticas implantadas em contraposição ao programa eleitoral triunfante, como na década de $1990 .{ }^{2}$ O governo que se instaurava em dezembro de 2015 reivindicava ser uma direita moderna e democrática para derrotar o "populismo" encarnado pelo "kichnerismo".

No debate de política econômica, as lideranças do novo governo defenderam a eficiência de políticas de abertura e liberalização, incluindo a financeira e cambial, como forma de desenvolver as "vantagens comparativas" da economia argentina. Além disso, rejeitaram qualquer possibilidade de restrição externa e efeitos do tipo de câmbio na inflação na medida em que operasse uma livre flutuação cambial e o financiamento externo ancorados em um equilibro fiscal e monetário (VANOLI; CIBILS; ALLAMI, 2018).

Ao final do governo Cambiemos, as promessas de fazer a Argentina "voltar ao mundo" e, com isso, promover o crescimento econômico, a redução da inflação e o fim a pobreza nunca estiveram mais longe de serem cumpridas. Este artigo procura

\footnotetext{
1 Os autores gostariam de agradecer as observações dos pareceristas e a editora da revista pelo trabalho.

2 Carlos Menem foi eleito em 1989 com uma plataforma clássica peronista de preservação dos salários e de políticas redistributivas. Porém, após dois anos de tentativas frustradas de lidar com a inflação e o baixo crescimento, implementou um programa liberal a partir da chegada de Domingo Cavallo ao ministério da economia.
} 
analisar a trajetória da economia argentina sob o governo de Mauricio Macri a partir: (i) de uma análise das reformas econômicas promovidas no seu primeiro ano de governo; (ii) dos resultados macroeconômicos destas medidas; (iii) da crise econômica e dos acordos firmados com o FMI. Por fim, faremos algumas considerações finais a respeitos das perspectivas econômicas que se apresentam para a Argentina nos próximos anos.

\section{O PLANO ECONÔMICO DE CAMBIEMOS}

Em 2015, a economia argentina chegava às vésperas da eleição em uma situação desfavorável. Se o crescimento econômico vivenciado desde a segunda metade de 2002, após grave crise de 2001, foi o maior registrado na história econômica recente do país, a partir de 2012 o país passou a experimentar problemas no setor externo que afetaram negativamente seu desempenho. A economia estagnava e a inflação mantinha-se em níveis elevados (AMICO, 2013). Nesta conjuntura, uma coalizão política liderada por Maurício Macri conseguiu, pela primeira vez na história do país, chegar ao poder através do voto popular com um programa econômico declaradamente liberal (NATANSON, 2018).

Segundo a equipe econômica de Macri, a fragilidade da economia argentina era resultado de anos de intervenção excessiva do Estado e de uma inserção internacional que teria isolado a Argentina do resto do mundo. Seria necessário, nas suas palavras, "voltar ao mundo" e promover reformas econômicas que resultassem num melhor ambiente de negócios para que uma "chuva de investimentos" estimulasse o retorno do crescimento econômico. Tratava-se de promover uma nova inserção externa. Após anos de isolamento dos mercados financeiros internacionais e, a partir de 2011, com aumento da regulação do comércio exterior, o novo governo se propunha a abrir novamente a economia Argentina.

A estratégia de desenvolvimento ficou conhecida publicitariamente como "Modelo Canguru", por ser pretensamente baseada na economia australiana. A abertura econômica seria acompanhada do estímulo aos setores naturalmente competitivos da argentina, ligados a agropecuária e a mineração, que garantiriam que a Argentina se tornasse, nas palavras do novo presidente, “o supermercado do mundo" (MACRI..., 2017).

$\mathrm{O}$ "choque de confiança" que a equipe econômica de Cambiemos desejava nasceria de reformas econômicas nas quais o Estado perderia o protagonismo em prol do crescimento dos investimentos do setor privado (FREITAS; FERNANDES, 2017).

As reformas econômicas seriam promovidas a partir de medidas que desfizessem os vários controles regulatórios criados durante os governos kirchneristas e se voltaram 
sobre medidas que promovessem uma maior abertura da economia: liberalização financeira, cambial e do comércio exterior.

No que diz respeito à questão financeira, tratou-se primeiramente de liberalizar o mercado de câmbio com o fim do chamado "cepo cambial”, adotado pelo segundo governo Cristina Kirchner (2011-2015) e que consistia em um conjunto de medidas que dificultavam a saída de divisas e o acesso ao mercado oficial de dólares.

Inicialmente, o governo Macri estipulou um limite máximo à compra de dólares, por individuo ou empresa, de US\$ 2 milhões por mês, limite este ampliado em 2016 e eliminado em 2018. Ainda na esfera financeira, o Banco Central Argentino (BCRA) reduziu a obrigação de permanência dos capitais que entrassem no país de 365 para 120 dias, que posteriormente também foi eliminada, em 2017 (FANELLI; ALBRIEU, 2015; VANOLI; CIBILS; ALLAMI, 2018).

O comércio exterior também foi alvo de medidas desregulatórias. O novo governo tratou de eliminar as “Declarações Juradas de Antecipado de Importação", que serviam para restringir importações, adotas durante o último governo de Cristina Kirchner. No que diz respeito às exportações, eliminaram-se as "retenções as exportações", impostos que incidiam sobre vários produtos agropecuários com a finalidade de estabelecer uma diferença entre o preço de venda internacional e os preços cobrados no mercado doméstico. Outra medida adotada foi ampliar o período no qual os exportadores deveriam liquidar suas dívidas no mercado cambial argentino. Inicialmente, ampliou-se o prazo de 30 dias para cinco anos, depois para 10 anos e, finalmente, em 2017, eliminou-se a obrigação (CATAMUTTO; SCHORR; WAINER, 2016; SABATELLA, 2017).

Em vistas de promover a maior integração da economia argentina aos mercados financeiros internacionais, condição tida como essencial pela equipe econômica para a chegada da "chuva de investimentos", era necessário resolver o conflito com os chamados "Fundos Abutres".

O conflito começou com os “megacanjes” de 2005 e 2010, quando se renegociou a dívida externa argentina no mercado internacional. Por volta de $90 \%$ dos credores aceitaram as novas condições de juros e amortização, porém, os fundos abutres comparam $10 \%$ dos títulos e recusaram o acordo oferecido pelo governo argentino. O conflito se asseverou quando um juiz nova-iorquino, em 2012, deu ganho de causa a estes fundos. A despeito de apelações feitas pelo governo argentino, a Corte Suprema de Justiça dos EUA manteve o veredito em 2014 (NEMIÑA; VAL, 2018).

\footnotetext{
3 Estes são fundos especializados em renegociar títulos de países que não pagaram ou renegociaram suas dívidas no mercado internacional. Seu ganho está em comprar estes papéis a preços muito reduzidos e vende-los após uma renegociação com os países emissores.
} 
O problema principal não eram apenas estes títulos de posse dos Fundos Abutres. Havia uma cláusula chamada RUFO, ${ }^{4}$ incluída nos acordos de renegociação, que significava a transferência automática de qualquer nova proposta mais favorável a todos os credores, ou seja, o pagamento aos Fundos Abutres colocava em risco toda a renegociação anterior.

Em fevereiro de 2016, após duras negociações no congresso nacional, Macri anunciava um acordo com os Fundos Abutres através de um pagamento de US\$ 9,3 bilhões. Desta forma, completava-se a estratégia de retorno aos mercados financeiros internacionais (NEMIÑA; VAL, 2018). ${ }^{5}$

Ainda sob a ótica do choque de confiança, o Governo Macri promoveu uma série de reajustes nas tarifas de bens públicos. A equipe econômica entendia, que durante os governos kirchneristas, estas tarifas estavam muito subsidiadas e ficaram muito defasadas, desestimulando os investimentos privados. Para uma inflação acumulada de $150 \%$, entre outubro de 2015 a outubro de 2018, estes “tarifazos" significaram aumentos de $1.053 \%$ a $2.388 \%$ na tarifa de eletricidade, de $462 \%$ a $1.353 \%$ no gás (aumentos variam de acordo com o consumo) e de $832 \%$ no consumo de água (CIFRA, 2019).

Para além do choque confiança, a equipe econômica de cambiemos via na questão do déficit público e na inflação, obstáculos fundamentais para a promoção do crescimento econômico. A interpretação era de que uma estratégia de combate a inflação partiria da necessidade de um maior aperto das contas do governo. Embora fossem necessárias medidas mais diretas para combater o crescimento dos preços, entendia-se que a raiz do processo estava na geração de déficits fiscais que promoviam uma pressão de demanda sobre a economia argentina, cuja resposta era a inflação (FIORITO, 2020).

Desse modo, inicialmente o Governo Macri teria se comprometido a um programa de ajuste fiscal com objetivo de reduzir o déficit público e, com relação ao combate a inflação, a adoção de um regime de metas de inflação ao final do primeiro ano de governo. A taxa de juros era o elemento fundamental. Tratava-se de colocar um "preço" elevado no dinheiro para que o mesmo saísse de circulação de forma a reduzir a demanda para que se reduzisse a pressão sobre os $\operatorname{preços}^{6}$ (AMICO, 2020).

As reformas econômicas foram iniciadas já no primeiro ano do governo Cambiemos. A despeito de a oposição popular ter reduzido o ímpeto do governo em algumas das reformas, principalmente a trabalhista, houve grande avanço nas reformas pró-mercado. Após a abertura da economia, a Argentina esperava os frutos dos

4 Rights Upon Future Offers.

5 Tratou-se de um acordo com 85\% dos Fundos. Em janeiro de 2019, um novo fundo acionou a Argentina nas cortes de Nova Iorque (AMICO, 2020).

6 Inicialmente também havia a intenção de flexibilizar as leis trabalhistas. Porém, após grandes protestos nas ruas do país, o governo abandonou tal ideia. 


\section{DO LIBERALISMO AO POPULISMO TARDIO}

Os primeiros resultados econômicos do governo Macri não foram auspiciosos. O resultado do conjunto de medidas econômicas no primeiro ano foi uma queda de $1,8 \%$ do PIB em 2016 (Gráfico 1). A política econômica cumpriu seu objetivo de retrair a demanda como forma de combater a inflação, no entanto, a desvalorização cambial que seguiu o fim do cepo cambial e o elevado aumento nas tarifas públicas provocaram uma grande queda do poder aquisitivo da população.

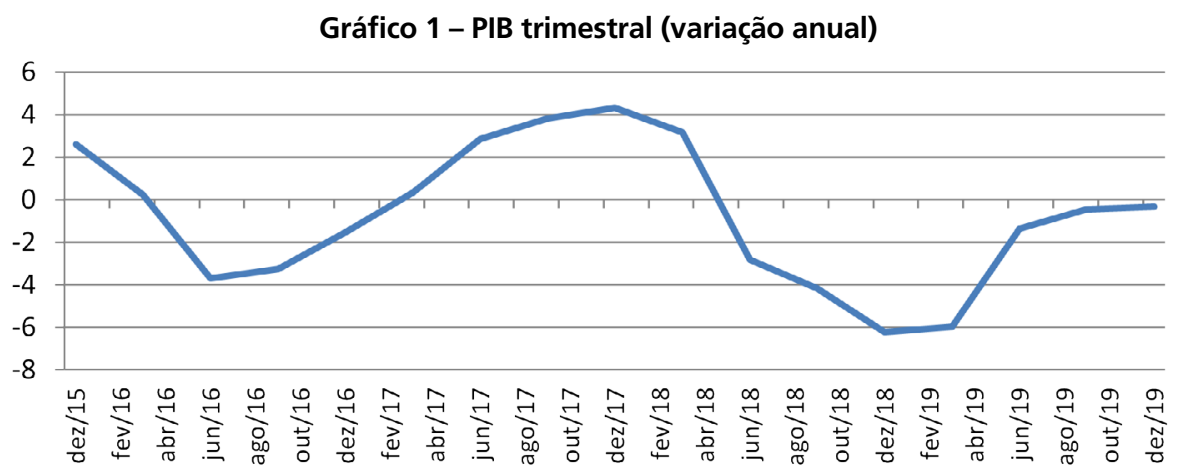

Fonte: Elaboração própria com base em dados de INDEC (2020a).

Para completar o quadro recessivo, os investimentos não se recuperaram. A despeito do discurso de "choque de confiança" e sua pouca factibilidade para incentivar os investimentos, uma política de liberação do comércio exterior e conseguinte alta nas importações, aliadas a elevada ociosidade da capacidade instalada, impediram a recuperação da formação bruta de capital fixo (FREITAS; FERNANDES, 2017).

As contas públicas não se comportaram da forma como o governo previu. Pelo lado das receitas, elas já teriam seu comportamento prejudicado pela queda na atividade econômica, mas houve também o impacto das medidas adotadas pelo governo: fim dos impostos sobre as exportações, reduções tarifárias promovidas nos setores de mineração e agropecuários e a redução nos impostos sobre lucro. Elas contribuíram para a queda da arrecadação do governo de 20,6\% do PIB em 2015 para 20,2 \% do PIB em 20167 (CIFRA, 2018).

Por outro lado, os gastos mantiveram-se no nível do ano anterior $(24,4 \%$ do PIB e 24,5\% do PIB em 2016). As despesas com subsídios econômicos, principalmente dos

\footnotetext{
7 A este total se somam os recursos oriundos do "blanqueo de capitales". Perdão oferecido pelo governo a quem possuía recursos não declarados no exterior. Descontando este efeito, a arrecadação cai para $19 \%$.
} 
setores de transporte e energia e com investimentos públicos, entretanto, houve aumento nas transferências para o setor privado. $O$ resultado foi uma elevação do déficit primário, de -3,9\% do PIB, em 2015, para -4,6\% do PIB, em 2016 (CIFRA, 2018).

Em relação à inflação, peça fundamental no esquema de melhora no ambiente de negócios, os resultados não foram melhores. A inflação acelerou em 2016 com relação a 2015 (Gráfico 2). A visão inicial do governo era de que a inflação se alimentava de um excesso de demanda que se manifestava através da monetização do déficit público. Partindo dessa hipótese, o governo deveria controlar a demanda via redução do deficit público. Embora tenha havido aumento do deficit, ele foi financiado via endividamento externo. Ainda assim, a economia experimentou uma queda na demanda, com recuo na base monetária e alta na taxa de juros.

\section{Gráfico 2 - Inflação versus taxa de câmbio}

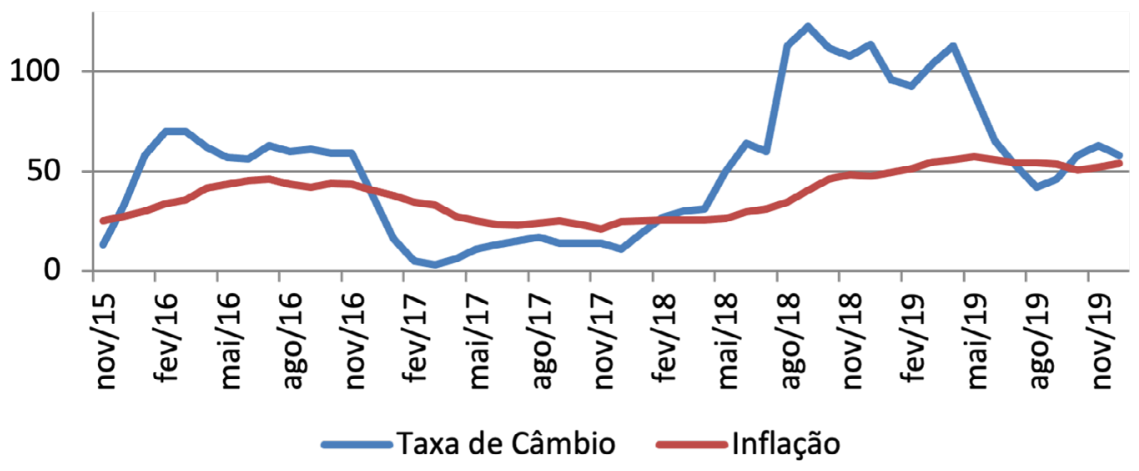

Fonte: Elaboração própria com base em dados da taxa de inflação até 2017 do Congresso Argentino (2020), dados da taxa de inflação após 2017 do INDEC (2020a) e dados da taxa de câmbio do Banco Central da República Argentina (BCRA, 2020).

Segundo Fiorito (2020), a dinâmica da inflação argentina responde as suas vicissitudes sociais, tornando o conflito distributivo ainda mais acirrado do que em outros países da América Latina. Sendo assim, após a deflagração de algum choque de custos na economia, há uma modificação na distribuição funcional da renda que deflagra o acirramento deste conflito. O resultado é uma espiral inflacionária. Como apresentado anteriormente, no caso do primeiro ano do governo Macri, a aceleração da inflação pode ser creditada a duas causas principais: a desvalorização cambial sofrida após o fim do cepo cambial e ao tarifazo sofrido pelos serviços públicos. Ambos serviram de gatilho para a aceleração do ritmo da inflação (WAHREN; HARRACÁ; CAPPA, 2017).

Seu impacto foi mais sentido pelas classes assalariadas que viram seu poder aquisitivo se reduzir com a queda sofrida pelo salário real. Segundo o Ministério do Trabalho argentino (2020), o salário-mínimo sofreu uma perda real de 5,3\% em 2016. 
Ela foi acompanhada de uma queda real da remuneração média dos trabalhadores que tiveram uma alta nominal de $24,3 \%$ no período, o que, contra uma inflação de $40,7 \%$, resultou numa perda real de 16,4\% (INDEC, 2020b). Todos estes fatores promoveram uma queda da massa salarial de 44,5\% do PIB em 2015 para 43,8\% do PIB em 2016 (KENNEDY et al., 2018).

$\mathrm{O}$ fracasso das iniciativas de reduzir a inflação levou a equipe econômica a alterar sua estratégia e optar pela adoção de um regime de metas de inflação. Anunciado em fins de 2016 para começar a ser aplicado em 2017, tratava-se de uma tentativa de controlar a inflação via administração da demanda através da taxa de juros. Foram adotadas como metas para 2017 um piso de $12 \%$ e um teto de $17 \%$ e, para 2018 , o planejado havia sido piso de $8 \%$ e teto de $12 \%$ (BCRA, 2019).

A queda da atividade econômica em 2016 teve forte impacto negativo no que tange à questão social. A taxa de desemprego sofreu um aumento de aproximadamente $30 \%$, passando de 6,5\%, em 2015, para 8,5\%, em 2016 (INDEC, 2020b). Um resultado expressivo para um governo que tinha com um dos motes de sua campanha "pobreza cero".

O primeiro ano chega ao fim com discussões internas do governo. Para uma parte da equipe econômica os números ruins do primeiro ano resultaram de certo gradualismo na adoção do programa liberal. Isto prejudicou a construção de expectativas favoráveis no setor privado, inibindo o crescimento do investimento (VANOLI; CIBILS; ALLAMI, 2018).

\subsection{O POPULISMO TARDIO}

A despeito da interpretação mencionada anteriormente, a chegada de um ano de eleições parlamentares levou a uma revisão das reformas pró-mercado no curto-prazo. Adotaram-se medidas de estímulo à demanda e intervenções no mercado cambial. As reformas liberais ficaram em suspenso e deram lugar a um período de "populismo tardio" (AMICO, 2020).

A partir de maiores intervenções no mercado de câmbio, o peso experimentou um período de leve valorização. Este processo foi alimentado pelo retorno da Argentina ao mercado financeiro internacional com a colocação de novos títulos de dívida soberana que alimentaram a entrada de dólares no país em 2017.

Como se poderia esperar, devido ao grande efeito do câmbio no comportamento dos preços, houve uma resposta imediata da inflação. A queda no ritmo de crescimento dos preços, de 40,8\%, em 2016, para 24,8\%, em 2017, restaurou o patamar inflacionário que o governo Cambiemos encontrou quando assumiu, em meados de 2015.

O efeito mais imediato deu-se sobre o nível de salários reais. Os trabalhadores conseguiram uma leve recuperação de seu poder de compra da ordem de $2,4 \%$ em 
relação a 2016, ainda assim, insuficiente para recuperar a perda do ano anterior. Já o salário-mínimo permaneceu praticamente estagnado com uma leve perda de 0,3\% (INDEC, 2019). Este resultado promoveu um aumento no consumo das famílias, o que contribuiu positivamente a alta da demanda no ano de 2017.

Outro fator decisivo para o comportamento positivo da demanda foi a elevação no gasto público. A despeito da queda de arrecadação do governo no período $19,3 \%$ do PIB em 2017 contra 20,2\% em 2016 e de um déficit primário menor que do ano anterior (- 3,9\% do PIB), o volume de gastos cresceu em 21,7\% (CIFRA, 2018).

Embora o investimento público tenha retrocedido e o governo tenha cortado os subsídios aos serviços públicos, houve um aumento de $36,7 \%$ de gastos em programas sociais, aposentadorias e pensões. Esses recursos representaram um aumento do poder de compra das classes mais pobres do país (CIFRA, 2018).

Todos estes fatores mencionados acima promoveram uma alta de 2,9\% do PIB em 2017, o melhor resultado que o governo Macri alcançaria. Porém um obstáculo para que este crescimento se sustentasse por um período mais longo retornava com força: a restrição externa.

Gráfico 3 - Setor externo (em milhões de dólares)

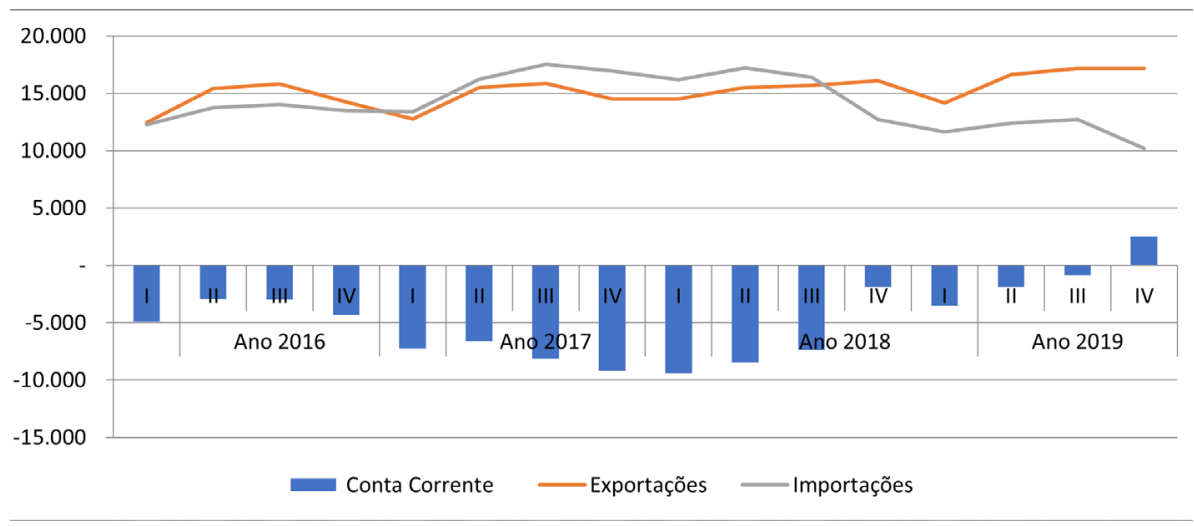

Fonte: Elaboração própria com base em dados de INDEC (2020a).

Os últimos dois anos do segundo governo de Cristina Kirchnner foram marcados por uma piora nas contas externas. Conforme demonstrado no Gráfico 3, durante todo o ano de 2015 a economia argentina apresentou déficits em conta corrente, incluindo uma balança comercial negativa na segunda metade do ano. Para um país que não contava com acesso aos mercados financeiros internacionais, após o default de 2007 e as renegociações de 2010, como veremos mais a frente, tratava-se de uma situação extremamente delicada (CANTAMUTTO; SCHORR; WAINER, 2016). 
Simultaneamente, desde o ano de 2007, o país começou a sofrer uma contínua saída de capitais. Parte da saída é explicada pelo pagamento da dívida externa através do uso das reservas internacionais. Outra parte da saída teria origem na persistente valorização da taxa de câmbio (e dos salários medidos em dólares) e a criação de crescentes pressões e expectativas favoráveis a uma desvalorização do peso (AMICO; DE MIGUEL, 2018).

Em resposta, o governo Kirchner adotou controles mais rígidos na movimentação de capitais e no comércio exterior, como forma de evitar um descontrole maior nas contas externas. Ao mesmo tempo, buscou uma reaproximação com os mercados financeiros internacionais como uma fonte alternativa de divisas. Porém, o conflito com os Fundos Abutres havia impedido qualquer chance de sucesso.

O governo Macri, conforme vimos, já em suas primeiras medidas procurou liberalizar o mercado de câmbio e o comércio exterior. Num primeiro momento, houve uma recuperação na balança comercial, com uma melhora nas exportações e queda nas importações, estas devido ao fraco desempenho do PIB em 2016.

No entanto, a recuperação econômica de 2017 estimulou um crescimento das importações, que atingiu o maior valor na história do país, cerca de US\$ 31 bilhões, contra um desempenho mais fraco das exportações. (INDEC, 2020a). Os déficits em conta corrente, que haviam diminuído em 2016, voltaram a crescer.

Foi a partir de uma estratégia distinta da adotada pelo governo de Cristina Kirchner que Macri procurou enfrentar este problema. As reformas pró-mercado serviriam para gerar confiança nos agentes econômicos e com isso atrair investimentos externos para ao país, mas esta estratégia não foi bem-sucedida. O volume de recursos oriundos desta conta sofreu apenas um leve crescimento, passando de U\$ 2,29 bilhões no último ano do Governo de Cristina Kirchner para US\$2,42 bilhões, em 2016 (WAHREN; HARRACÁ; CAPPA, 2017).

No entanto, a liberalização do câmbio pelo governo foi acompanhada por um processo de endividamento externo. Esta entrada de dólares serviu para cobrir os déficits em conta corrente, assim, o alívio oferecido pelas medidas no curto-prazo haveria de cobrar um preço muito alto pouco tempo depois.

Após as vitórias nas eleições parlamentares e com a melhora no crescimento econômico em 2017, o governo Macri anunciava que finalmente as reformas estavam trazendo resultados positivos e a melhora no ambiente de negócios faria com que a argentina experimentasse um crescimento sustentável de longo prazo.

A economia argentina não foi capaz de repetir o mesmo desempenho no ano seguinte. Os impactos da liberalização financeira e do comércio exterior fragilizaram muito a posição externa do país. A restrição externa que havia constrangido o crescimento nos últimos anos kirchneristas havia retornado. Desta vez não por causa de um crescimento 
robusto da economia, mas devido à especulação financeira e ao endividamento em dólares estimulado pelas medidas econômicas do governo Macri.

\section{CRISE E O RETORNO AO FMI}

Durante os governos kirchneristas, a economia argentina passou por um processo de desendividamento, que reduziu muito a relação dívida externa/PIB do país e permitiu o pagamento das dívidas com o FMI e a formação de reservas internacionais depois da maior crise econômica do país em 2001. O processo ocorreu através da renegociação dos títulos de dívida do governo argentino no mercado internacional.

Conforme visto anteriormente, a equipe econômica do governo Macri imediatamente desmontou o aparato regulatório cujo objetivo seria facilitar o investimento estrangeiro direto como forma de retomar o crescimento econômico. Porém, na prática, transformou-se em um grande esquema financeiro responsável pelo reendividamento externo do Estado e o crescimento dos passivos externos do setor privado, resultando num aumento da vulnerabilidade externa da economia argentina.

A liberalização financeira permitiu a entrada de capitais de curto-prazo que vinham se aproveitar das condições favoráveis de rentabilidade da economia argentina. A alta na taxa de juros iniciada em 2016, aliada à política de câmbio flutuante que, após a desvalorização e o fim do "cepo cambial”, permaneceu estável, garantia uma alta rentabilidade em dólares ao investidor externo (AMICO, 2020).

Por outro lado, o setor privado argentino é um grande demandante de dólares. Com a liberalização, formou-se um novo canal de saída de dólares, que facilitou as operações dos grandes grupos empresariais argentinos, o envio dos lucros das multinacionais para o exterior feito e a compra de dólares pelas famílias mais ricas do país. Este processo aumentou a dolarização da economia do país.

Durante os governos kirchneristas, houve uma preocupação em aumentar a pesificação dos ativos financeiros domésticos. Esta tendência foi revertida durante o governo Macri, a partir das portarias do Banco Central Argentino de permitir novamente a emissão de instrumentos de crédito de empréstimos em dólares pelos bancos argentinos (BCRA, 2016).

Logo ao assumir, o governo Macri acertou-se com os Fundos Abutres através da emissão de títulos de dívida da ordem de US\$ 16 bilhões nos mercados financeiros internacionais. Apenas nos dois primeiros anos do governo Macri, a dívida externa do governo argentino experimentou um crescimento de pouco mais US\$ 39 bilhões, o equivalente a $60 \%$ do estoque de dívida que o país possuía em 2015 , sendo que US\$ 30,1 bilhões foram de caráter público. Tratou-se do maior incremento da 
história da argentina, superando períodos como a Guerra das Malvinas (US\$ 21 bilhões) e o governo do presidente Carlos Menem (US\$ 14 bilhões, em 1994) (MANZANELLI; BARRERA, 2018).

\section{Gráfico 4 - Dívida externa (milhões de dólares)}

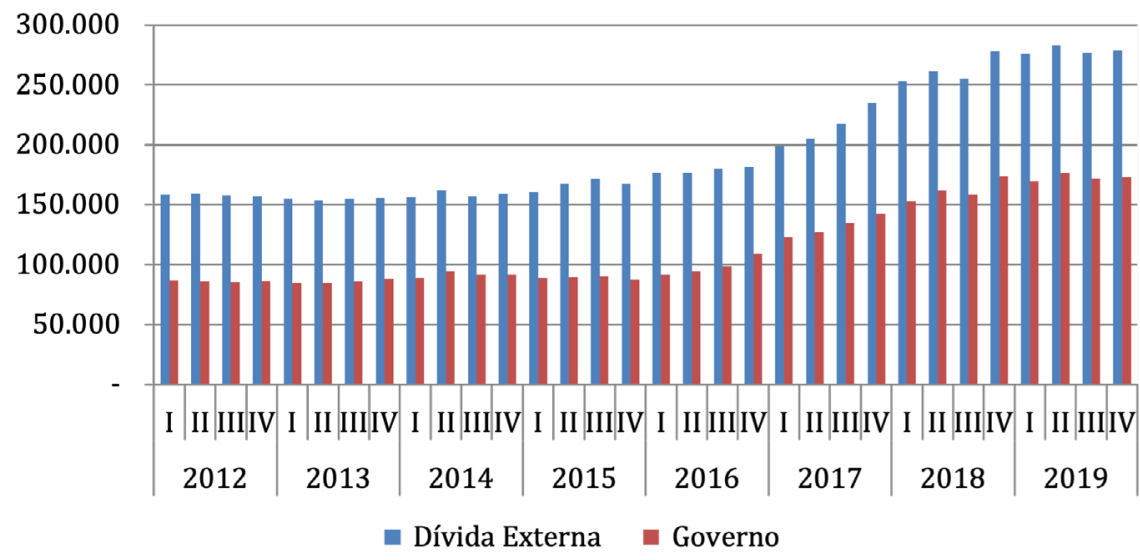

Fonte: Elaboração própria com base em dados de INDEC (2020a).

Muito embora esta aceleração do endividamento esteja estreitamente relacionada com o processo de liberalização financeira, ele não foi o único fator. O retorno dos déficits em conta corrente a partir de 2017, como visto anteriormente, com a liberalização do comércio exterior, exerceram uma significativa pressão sobre a demanda de dólares.

Concomitante a esta aceleração do endividamento externo, a saída de capitais atingiu US\$ 21 bilhões nesse mesmo período. Em 2016, o montante foi de apenas US\$ 3 bilhões, devido à grande entrada de capitais proporcionada pela rentabilidade das LEBACS ${ }^{8}$, mas também pelo perdão que o governo argentino ofereceu a quem possuía dólares não declarados no exterior, "el sinceramiento fiscal". A saída de capitais se acelerou em 2017 e foi da ordem de US\$ 11 bilhões (BARRERA; BONA, 2018).

Desta forma, as medidas de liberalização econômica nos dois primeiros anos do governo Macri alimentaram um explosivo esquema que promoveu a saída de capitais que se financiou pelo endividamento externo público nos mercados internacionais.

Este processo passou a enfrentar limites a partir do início de 2018. Por um lado, internamente, a adoção de uma política de juros mais baixos, combinada com a

\footnotetext{
8 "Letras del Banco Central".
} 
desvalorização sofrida pelo peso, estrangulou a rentabilidade em dólares das LEBACS, o que gerou ao mesmo tempo uma queda na entrada e uma aceleração na saída de dólares (AMICO, 2020).

Por outro lado, as condições dos mercados financeiros internacionais alteraram-se bruscamente com o anúncio da elevação da taxa de juros nos Estados Unidos. Os investidores estrangeiros refizeram suas análises de risco e retorno, concluindo por evitar a exposição em moedas de mercados periféricos tidos como instáveis. Esta mudança de atitude atingiu em cheio a Argentina.

O resultado foi uma corrida cambial que gerou grande perda de reservas pelo Banco Central Argentino. Este processo foi alimentado não só por investidores externos, como também pelo setor privado argentino que acelerou o ritmo de saída. Entre os meses de janeiro e maio de 2018, o Banco Central Argentino experimentou uma queda em suas reservas de pouco mais que US\$ 8 bilhões. Durante esse período, o presidente Macri e seu ministro da economia, Prat Gay, afirmaram repetidas vezes que não havia riscos e que não iriam retornar ao FMI (FIORITO, 2020). Porém, em maio de 2018, o governo argentino envia uma solicitação de acordo com o fundo. Tratava-se de se recuperar a “confiança dos mercados” para frear a corrida cambiária.

\subsection{O RETORNO AO FUNDO}

O acordo, assinado em junho de 2018, tornou-se o maior da história da Argentina com o FMI, da ordem de US\$ 50 bilhões de dólares, equivalendo a 80\% do total de empréstimos do FMI ao país nos últimos 40 anos (MANZANELLI; BARRERA, 2018).

$\mathrm{O}$ diagnóstico da crise apresentado pelo governo argentino e pelo FMI era que a economia argentina estava sofrendo de um descontrole nos gastos públicos gerando um déficit fiscal que pressionava a demanda e, por conseguinte, a inflação. Entendia-se que a situação havia piorado devido a uma seca que provocou a queda a produção agropecuária e, por conseguinte, reduziu as exportações do país, e que, por fim, uma mudança nos mercados financeiros internacionais, que serviu para desatar a crise (IMF, 2018). O país precisava, de acordo com o governo e o FMI, ganhar novamente a confiança dos investidores através de um novo conjunto de medidas econômicas acordadas pelo governo com os técnicos do fundo.

Primeiramente, acertou-se, nas palavras do próprio fundo, um "ambicioso ajuste fiscal” (IMF, 2018). O ajuste se daria através do corte de gastos públicos, privatizações, fim de subsídios e redução de salários e do número de empregos públicos. Também se esperava uma elevação nas receitas públicas de aproximadamente $20 \%$, em 2018 , e de 
19\%, em 2019. A meta era reduzir o déficit primário de $-3,8 \%$ do PIB, em 2017, para -2,7\%, em 2018, -1,3\%, em 2019, para até, finalmente, zerá-lo em 2020 (IMF, 2018).

Em seguida, ficou acertada uma nova política cambial. O Banco Central Argentino (BCRA) ficou responsável por estabelecer uma política de bandas cambiais. Entre o valor de piso e o valor de teto, inicialmente fixados entre 34 e 44 pesos, respectivamente, o mercado flutuaria livremente. Caso o valor se aproxime do teto/piso o BCRA poderia vender/comprar divisas na ordem de US\$ 150 milhões por dia. Também foi acordada a manutenção do regime de metas de inflação. Incialmente foi acordado que a inflação anual não deveria passar de $32 \%$ em 2018 e ir reduzindo-se gradualmente até atingir 9\% em 2021 (IMF, 2018).

Acordou-se também um piso para as reservas do Banco Central. Elas deveriam permanecer maiores que US\$ 5,5 bilhões até junho de 2019 e crescerem até atingir US\$ 28 bilhões em junho de 2021. Isto implicava que o governo tomasse medidas para reduzir o deficit em conta corrente através da geração de saldos comerciais, mas também reduzindo a saída de capitais (IMF, 2018). As expectativas do FMI com relação aos resultados do acordo baseavam-se num baixo crescimento do PIB em 2018 (0,4\%) e numa recuperação maior em 2019 (1,5\%). Esta perspectiva se balizava numa expansão acelerada das exportações em 2018 e 2019 da ordem de 5,6\% e 6,8\%, respectivamente (IMF, 2018).

Esse acordo inicial não duraria muito e os resultados voltaram a ser decepcionantes. A primeira parcela de US\$ 15 bilhões liberada pelo FMI não foi capaz de reduzir a corrida cambial. O montante foi consumido em pouco mais de três meses. Em setembro de 2018, o governo argentino acertou um novo acordo com fundo que alterou o cronograma de liberalização de recursos. Em junho de 2019, após a quarta revisão do acordo com os técnicos do FMI, o país foi autorizado a sacar mais US\$ 5,4 bilhões. Naquela altura, a Argentina já havia sacado U\$44,1 bilhões do total de US\$ 50 bilhões estabelecido no acordo original (IMF, 2019).

A equipe do FMI fez uma análise positiva da recuperação da economia argentina após a corrida cambial de 2018 (IMF, 2019), mas os números não mostraram muita razão para otimismo. No front interno, o ajuste recessivo resultou em uma contração da economia maior do que a perspectiva adotada pelo FMI, com uma queda de 2,5\% do PIB em 2018. Essa queda não foi revertida no ano seguinte. Embora os últimos meses de 2019 tenham apresentado uma leve recuperação econômica, o último ano do governo Macri apresentou uma nova queda no PIB de 2,1\% (INDEC, 2020a). Dos quatro anos de governo Cambiemos apenas um (2017) apresentou crescimento econômico. 
Contribuiu muito para esta recessão dos últimos dois anos a forte redução do gasto público, que em termos reais caiu 8,9\% e 12,9\% em 2018 e 2019, respectivamente. Houve queda nas transferências sociais e nos subsídios econômicos, além da redução de gastos com obras públicas. No entanto, houve uma leve queda no resultado primário, através da geração de déficits da ordem de -2,3\% em 2018 e -3,0\% em 2019 (CIFRA, 2020).

Outro fator que importante para a recessão econômica foram as taxas de juros. Foram fixadas em níveis elevados, pouco mais de $70 \%$ ao ano em outubro de 2018 , como forma de conter a crise cambial. Conforme é possível observar no Gráfico 5, ela começou o ano de 2019 estabilizada num nível menor, porém ainda elevado, de cerca de $50 \%$. No entanto, o Banco Central foi obrigado a subir a taxa novamente ao patamar dos $70 \%$ nos meses de agosto e novembro, em grande parte devido a especulações no mercado cambial devido a aproximação das eleições.

As reservas do Banco Central recuperam-se das perdas ocorridas com a crise cambial e atingiram, em janeiro de 2019, um montante próximo a US\$ 66 bilhões, nível equivalente ao do início de 2018 (BCRA, 2019). Porém o risco país continuava elevado, embora estável, sinalizando que os operadores financeiros internacionais não se convenceram que a tutela do FMI e as medidas adotadas pelo governo argentino iam a reduzir a fragilidade financeira do país.

\section{Gráfico 5 - Taxa de juros x risco-país}

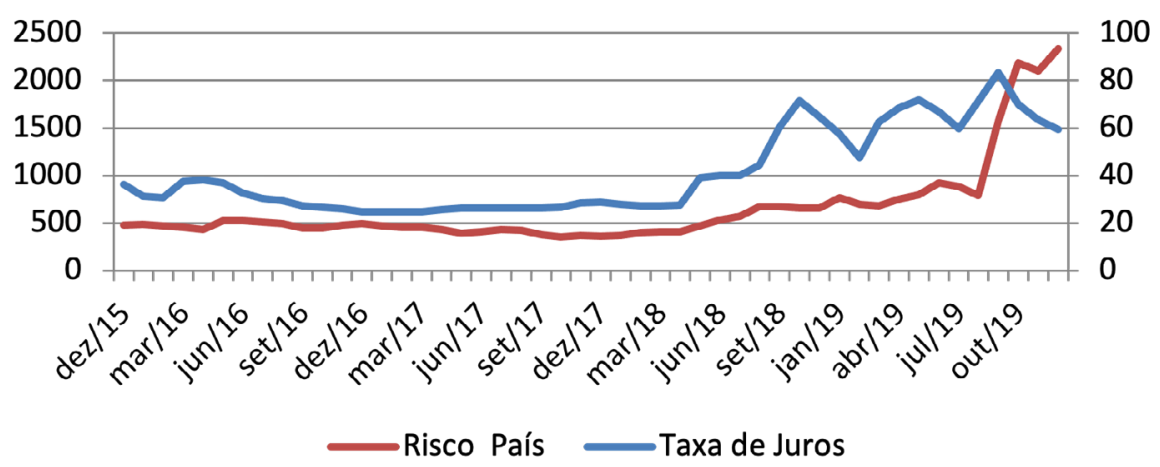

Fonte: Elaboração própria com base em dados da taxa de juros do Banco Central da República Argentina (BCRA, 2020) e dados do risco-país de J. P. Morgan (2020).

Assim, as turbulências externas retornaram a Argentina no último ano da administração Macri. Apesar do apoio ao governo argentino, o próprio Fundo enxergava um elevado risco oriundo tanto das eleições presidenciais, como do grande volume de pagamentos externos que o país deveria honrar até o fim de 2019 (IMF, 2019). 
Tal combinação de fatores foi fundamental para mais uma corrida contra o peso, que o país enfrentou imediatamente após a derrota nas eleições primárias em agosto de 2019. A desvalorização afetou diretamente a já elevada inflação argentina como também fragilizou a posição do país frente aos próximos compromissos externos.

No acordo com o Fundo, a expectativa era de que a inflação reduziria seu ritmo a partir de 2018, quando marcava 27\%, para chegar a 17\% em 2019 e, por fim, atingir um dígito, ficando em 9\%, em 2021 (IMF, 2018). Porém, a taxa de inflação disparou, em 2018: o índice anualizado atingiu 49,3\% em janeiro de 2019 contra $25 \%$ em janeiro de 2018. E terminou o ano de 2019 na casa dos 53,8\% (INDEC, 2020).

O presidente Macri decretou um default seletivo que recaiu sobre alguns títulos de dívida pública denominadas em peso, e fez um pedido ao FMI para que se alongasse o prazo dos desembolsos previstos no cronograma original do acordo em vigência (ZAIAT, 2019).

A derrota para Alberto Fernandez nas eleições presidenciais de 2019 decretou o fim do governo Macri. As duas quedas consecutivas do PIB (2018 e 2019) deixaram o índice de desemprego em 8,9\% em dezembro de 2019, após ultrapassar a casa dos $10 \%$ em junho do mesmo ano. As perdas salariais em decorrência da aceleração da inflação provocaram uma queda do salário real em torno de 10\% em 2019. Por fim, a Argentina possuía, em janeiro de $2020,40,9 \%$ da população abaixo da linha de pobreza. Um resultado frustrante para um governo que havia prometido zerar a pobreza em sua campanha eleitoral (INDEC, 2020a).

\section{CONSIDERAÇÕES FINAIS}

Ao final do governo de Maurício Macri a Argentina se tornou uma economia menor, mais endividada e mais pobre. O PIB apresentou queda em todos os anos, menos 2017. A inflação disparou e terminou o ano de 2019 num patamar duas vezes maior do que estava em 2015. Os salários não conseguiram acompanhar o ritmo dos preços provendo uma queda significativa do poder aquisitivo da população. O saláriomínimo perdeu 27\% de seu valor entre 2015-2019, atingindo valor real próximo ao de 2004 (INDEC, 2020a). Os impactos sociais foram sofridos para grande parte da população. Cerca de $40 \%$ da população argentina encontrava-se abaixo da linha de pobreza ao final de 2019. Um resultado trágico para um país que se orgulhava de sua numerosa classe média.

Além dessa pesada herança social, Macri deixou para os próximos governos argentinos uma econômica bastante endividada. A dívida externa cresceu numa velocidade nunca vista na história do país. Esta dívida e o acordo com o FMI comprometerá a Argentina 
por muito tempo, representando um peso a mais numa economia que necessita voltar a crescer de forma sustentável para reverter a deterioração das condições sociais vivenciadas durante o governo Macri.

A adoção de típica política liberal de redução do Estado e promoção do mercado como fonte principal de crescimento econômico foi a razão principal deste fracasso. As reformas econômicas adotadas com vistas a promover uma "chuva de investimentos", conforme afirmação do Presidente Macri, promoveram uma queda no PIB e o fechamento de milhares de firmas. A liberalização cambial e financeira não foi capaz de atrair o investimento externo direto como previsto. Pelo contrário, resultaram numa enorme saída de capitais facilitada pelo endividamento externo que agravou a tradicional restrição externa e a dependência da econômica aos mercados internacionais.

Ocorreu um aprofundamento das tendências inflacionárias devido à persistente desvalorização da moeda. Tratou-se do agravamento de mecanismos e problemas econômicos bem conhecidos no debate latino-americano desde os trabalhos pioneiros de Raul Prebisch, mas negados pelo marco ideológico dos grupos liberais e conservadores argentinos.

Mas estes não são resultados exclusivos da economia argentina. Após a queda ou a derrubada de governos progressistas em quase toda região, a aplicação desta nova agenda de política econômica liberal em vários países da América do Sul, vem gerando resultados igualmente negativos, que agravam as perspectivas econômicas. Resta saber se as condições políticas permitirão a ascensão ao poder de governos com propostas econômicas alternativas como aconteceu com a Argentina em 2019.

\section{REFERÊNCIAS}

AMICO, F. Crecimiento, distribución y restricción externa en Argentina. Circus, Revista Argentina de Economía, n. 5, p. 31-80, 2013.

AMICO, F. La macroeconomía de Macri: Adiós represión financiera, bienvenido nuevo default. Circus: Revista Argentina de Economía, n. 7, p. 52-89, 2020.

AMICO, F.; DE MIGUEL, M. Cuando pase el temblor. El Economista, Buenos Aires, 2 maio 2021. Disponível em: https://bit.ly/3wzUCqX. Acesso em: 26 maio 2021.

BCRA - BANCO CENTRAL DE LA REPÚBLICA ARGENTINA. Informe de Política Monetaria. Buenos Aires: BCRA, out. 2016.

BCRA - BANCO CENTRAL DE LA REPÚBLICA ARGENTINA. Informe de Política Monetaria. Buenos Aires: BCRA, ago. 2019.

BCRA - BANCO CENTRAL DE LA REPÚBLICA ARGENTINA. Informe de Política Monetaria. Buenos Aires: BCRA, fev. 2020. 
BARRERA, M.; BONA, L. La fuga de capitales en la Argentina reciente (1976-2018). Revista Facultad de Ciencias Económicas: Investigación y Reflexión, v. 26, n. 2, p. 7-32, 2018.

CANTAMUTTO, F.; SCHORR, M.; WAINER, A. El sector externo de la economía argentina durante los gobiernos del kirchnerismo (2003-2015). Realidad Económica, n. 304, p. 41-73, 2016.

CIFRA - CENTRO DE INVESTIGACIÓN Y FORMACIÓN DE LA REPÚBLICA ARGENTINA. El balance fiscal de los dos primeros años del gobierno de Macri: Ajuste con crecimiento del déficit. Buenos Aires: CIFRA, 2018.

CIFRA - CENTRO DE INVESTIGACIÓN Y FORMACIÓN DE LA REPÚBLICA ARGENTINA. Informe de coyuntura, n. 30. Buenos Aires: CIFRA, 2019.

CIFRA - CENTRO DE INVESTIGACIÓN Y FORMACIÓN DE LA REPÚBLICA ARGENTINA. Evolución del salario mínimo, vital y móvil. Buenos Aires: CIFRA, 2020.

FANELLI, J.; ALBRIEU, R. Tempos difíceis. A macroeconomia argentina nos primeiros meses do governo Macri. Revista Brasileira de Comércio Exterior, v. 128, p. 28-35, 2016.

FIORITO, A. La inflación en tiempos macristas: La bancarrota intelectual del monetarismo en la Argentina. Circus: Revista Argentina de Economía, n. 7, p. 22-51, 2020.

FREITAS, A. J.; FERNANDES, M. P. Sobre fadas e confiança: Um ano de governo Macri. Brazilian Keynesian Review, v. 3, n. 1, 2017.

J. P. MORGAN. EMBI - Emerging Markets Bond Index. J. P. Morgan, 2020.

IMF - INTERNATIONAL MONETARY FUND. Argentina: Fourth review under the stand-by arrangement, request for waivers of applicability and modification of performance criteria, and financing assurances staff report; and staff supplement. Washington, DC: IMF, 2019.

IMF - INTERNATIONAL MONETARY FUND. Request for stand-by arrangement: Press release and staff report. Washington, DC: IMF, 2018.

INDEC - INSTITUTO NACIONAL DE ESTADÍSTICA Y CENSOS DE LA REPÚBLICA ARGENTINA. Índice de salários. [Online] INDEC, 2020a. Disponível em: https://bit.ly/ 2SwHAvT. Acesso em: 23 maio 2021.

INDEC - INSTITUTO NACIONAL DE ESTADÍSTICA Y CENSOS DE LA REPÚBLICA ARGENTINA. Mercado de Trabajo. [Online] INDEC, 2020b. Disponível em: https://bit.ly/ 2TlYZb1. Acesso em: 23 maio 2021.

KENNEDY, D.; PACÍFICO, L.; SÁNCHEZ, M. La massa salarial y su composición según el vínculo laboral, Argentina, 1993-2017. Documentos de Trabajo, n. 24. Buenos Aires: Centro de Estudios sobre Población, Empleo y Desarrollo, 2018.

MACRI pidió ser "el supermercado del mundo". Tiempo Argentino, Buenos Aires, 29 jul. 2017. Disponível em: <https://www.tiempoar.com.ar/politica/macri-pidio-ser-el-supermercadodel-mundo/>. Acesso em 13 out. 2020.

MANZANELLI, P.; BARRERA, M. Deuda externa y corrida cambiaria: Un análisis del gobierno de Cambiemos en perspectiva histórica. Cuadernos de Economía Crítica, v. 5, n. 9, p. 17-44, 2018.

NATANSON, J. Mauricio Macri en su ratonera: El fin de la utopía gradualista. Nueva Sociedad, n. 276, 2018. 
NEMIÑA, P.; VAL, M. E. El conflicto entre la Argentina y los fondos buitres: Consecuencias sobre los procesos de reestructuración de deuda soberana. CEC, v. 5, n. 9, p. 45-68, 2018.

O'DONNELL, G. Estado y Alianzas en la Argentina, 1956-1976. Desarrollo Económico, v. 16, n. 64, p. 523-554, 1977.

PORTANTIERO, J. C. Los usos de Gramsci. Mendoza: Editorial Tierra del Sur, 2019.

VANOLI, A.; CIBILS, A.; ALLAMI, C. Los cambios en la era Cambiemos: Adiós producción y consumo, hola (otra vez) especulación financiera. Revista Análisis, n. 36, p. 1-26, 2018.

VOMMARO, G. De la construcción partidaria al gobierno: PRO-Cambiemos y los límites del "giro a la derecha" en Argentina. Colombia Internacional, n. 99, p. 91-120, 2019.

WAHREN, P.; HARRACÁ, M.; CAPPA, A. A Tres años de Macri: Balances y perspectivas de la economía argentina. Buenos Aires: CELAG, 2018.

ZAIAT, A. El default de Macri. Página 12, Buenos Aires, 01 set. 2019. Disponível em: <https:// www.pagina12.com.ar/215629-el-default-de-macri >. Acesso em: 10 mar. 2020. 